\title{
The value of logbooks in learning the hidden curriculum and practicing written reflection
}

This article was published in the following Dove Press journal:

Advances in Medical Education and Practice

Nikhil Joshi'

Lorna Leandro ${ }^{2}$

Shivan Thakrar'

'School of Medicine, Imperial College London, London, UK; ${ }^{2}$ Medical

Sciences Division, University of

Oxford, Oxford, UK
Correspondence: Nikhil Joshi

School of Medicine, Imperial College

London, London, UK

Email ndj16@imperial.ac.uk

\section{Dear editor}

We read with great interest the article by Alabbad et $\mathrm{al}^{1}$ that showed a lack of correlation between the volume of self-reported clinical cases medical students completed and subsequent exam scores. However, we believe that logbooks have value outside of preparation for objective structured clinical examinations and written papers: ensuring students gain experience of the hidden curriculum and providing an opportunity to practice written reflection.

Medical students often find it difficult to learn in the clinical setting as they must actively seek out opportunities through self-directed learning. ${ }^{2}$ From our experience, having the objective of recording clinical cases in a logbook gives students a purpose and helps direct their approach, particularly when on hospital wards. Instead of disappearing to work in the library, students are encouraged to remain in clinical situations and see patients. Experiencing more clinical encounters increases students' exposure to the hidden curriculum.

The hidden curriculum represents areas of learning that fall outside the formal curriculum and are often unarticulated. ${ }^{3}$ It teaches the culture of working in the field of medicine, for example the development of a professional identity or learning to manage the emotional aspects of being a clinician. ${ }^{3}$ We believe that logbooks increase student engagement with the hidden curriculum, and, as a result, produce individuals better prepared for working as doctors.

Alabbad et al conclude that logbooks do not make good assessment tools, and we propose that they could provide an opportunity for reflective writing instead. Along with reporting a clinical case, students could be asked to record a written reflection of the experience in their logbook. By doing so, they would practice and develop a key skill found in the General Medical Council's guidance on "Outcomes for graduates": the doctor as a professional should continually and systematically reflect on practice. ${ }^{4}$ Reflections may include thoughts on the way a doctor handled a situation, the manner in which a patient reacted to information, or how well the student felt they performed a clinical examination.

In his guide on "The use of reflection in medical education", 5 Sandars sets out some of the common problems encountered and logbooks that include written reflections are well suited to remedying several of these. Firstly, they would be a formative aspect of the curriculum that students must complete, thus combatting low engagement in reflection. Secondly, they would promote integration of reflection within clinical teaching, as the written reflection would be considered alongside the clinical case, rather than an optional extra. Finally, if they require a signature from a clinical tutor 
for each case recorded, as used in the research Alabbad et al undertook, they would ensure that feedback is received through mandatory discussion of the logbook entry with the tutor. Therefore, alongside their role in ensuring student engagement with the hidden curriculum, we believe that logbooks offer an ideal opportunity for medical educators to ensure that students practice written reflection.

\section{Disclosure}

The authors report no conflicts of interest in this communication.

\section{References}

1. Alabbad J, Abdul Raheem F, Almusaileem A, Almusaileem S, Alsaddah S, Almubarak A. Medical students' logbook case loads do not predict final exam scores in surgery clerkship. Adv Med Educ Pract. 2018;9:259-265.

2. Teunissen PW, Westerman M. Opportunity or threat: the ambiguity of the consequences of transitions in medical education. Med Educ. 2011;45(1):51-59.

3. Cribb A, Bignold S. Towards the reflexive medical school: the hidden curriculum and medical education research. Stud High Educ. 1999;24(2):195-209.

4. General Medical Council. Outcomes for graduates (tomorrow's doctors). Manchester: General Medical Council; 2015. Available from: https://www.gmc-uk.org/-/media/documents/outcomes-for-graduatesjul-15-1216_pdf-61408029.pdf. Accessed August 9, 2018. 2015:1-18.

5. Sandars J. The use of reflection in medical education: AMEE Guide No. 44. Med Teach. 2009;31(8):685-695. 


\section{Authors' reply}

Jasim Alabbad ${ }^{1,2}$

Fawaz Abdul Raheem²

Ahmad Almusaileem'

Sulaiman Almusaileem'

Saba Alsaddah ${ }^{2}$

Abdulaziz Almubarak ${ }^{2}$

'Department of Surgery, Faculty of Medicine, Kuwait University, Safat, Kuwait City, Kuwait; ${ }^{2}$ Department of Surgery, Mubarak

Al-Kabeer Hospital, Jabriya, Kuwait

Correspondence: Jasim Alabbad

Department of Surgery, Faculty of Medicine, Kuwait University, P.O.

Box 24923, Safat I 3 I I0, Kuwait

Tel +96524636215

Email jasim.alabbad@hsc.edu.kw

\section{Dear editor}

We read the letter by Joshi et al and would like to thank them for their valuable comments regarding our work. ${ }^{1} \mathrm{We}$ agree that the concept of "the hidden curriculum" is a very important one. ${ }^{2}$ One of the main objectives from our paper is to attempt to correlate the progress done on the logbook with exam scores, and we found that higher volume of case encounters did not translate into better exam scores. It is important to note that the qualitative nature of these case encounters was not investigated and would provide more insight into the quality of these teaching opportunities. We point out that these results do not mean that the logbook should be foregone but perhaps should be redesigned to emphasize and standardize other aspects of "the hidden curriculum" of medicine such as professionalism, team building, and interpersonal interactions.

\section{Disclosure}

The authors report no conflicts of interest in this communication.

\section{References}

1. Alabbad J, Abdul Raheem F, Almusaileem A, Almusaileem S, Alsaddah S, Almubarak A. Medical students' logbook case loads do not predict final exam scores in surgery clerkship. Adv Med Educ Pract. 2018;9:259-265.

2. Lawrence C, Mhlaba T, Stewart KA, Moletsane R, Gaede B, Moshabela M. The hidden curricula of medical education: a scoping review. Acad Med. Epub 2017 Nov 7.

Dove Medical Press encourages responsible, free and frank academic debate. The content of the Advances in Medical Education and Practice 'letters to the editor' section does not necessarily represent the views of Dove Medical Press, its officers, agents, employees, related entities or the Advances in Medical Education and Practice editors. While all reasonable steps have been taken to confirm the content of each letter, Dove Medical Press accepts no liability in respect of the content of any letter, nor is it responsible for the content and accuracy of any letter to the editor.

\section{Publish your work in this journal}

Advances in Medical Education and Practice is an international, peerreviewed, open access journal that aims to present and publish research on Medical Education covering medical, dental, nursing and allied health care professional education. The journal covers undergraduate education, postgraduate training and continuing medical education including emerging trends and innovative models linking education, research, and health care services. The manuscript management system is completely online and includes a very quick and fair peer-review system. Visit http://www.dovepress.com/testimonials.php to read real quotes from published authors. 